\title{
Reduced Pupillary Light Reflexes in Diabetic Autonomic Neuropathy
}

\author{
S. A. Smith and S.E. Smith \\ Department of Pharmacology, St. Thomas's Hospital Medical School, London, UK
}

Summary. Infrared television pupillometry was performed in 71 healthy and 66 insulin-treated diabetic subjects. Resting pupil diameter and the amplitude of the reflex response to standard light flashes were measured in background darkness. In the healthy subjects with small pupils $(<6 \mathrm{~mm})$ the size of the light reflex was found to depend on the diameter of the pupil in darkness, the former decreasing by $0.55 \mathrm{~mm} / \mathrm{mm}$ decrease in diameter. A positive correlation was also found in the diabetic subjects with small pupils but the reflexes were much smaller for a given resting diameter than in healthy subjects. The majority of the diabetic patients with small pupils had autonomic neuropathy. It is suggested that impaired pupillary dilatation in diabetic subjects is due to a sympathetic neuropathy and the small light reflex response in some patients is due to parasympathetic dysfunction in addition.

Key words: Pupillary light reflex, pupillary diameter, diabetic neuropathy, autonomic dysfunction, age.
Autonomic neuropathy in diabetes commonly affects the pupil. The two most striking abnormalities are the small pupil size, even in darkness, and the reduced reflex response to light $[1,2]$. Since pupillary dilatation is sympathetically-mediated and constriction is parasympathetically-mediated, it appears that both branches of the autonomic innervation of the iris muscles are affected.

There are reasons, however, other than parasympathetic dysfunction which could underly the reduced light reflex amplitude. Pathology of the iris tissue itself $[3,4]$ could restrict its mobility although normal or enhanced responses to cholinomimetic drugs $[5,6]$ argues against this view. The presence of retinopathy may create an afferent defect but controlling for this does not restore reflex response [1]. Finally, it has been suggested that the small reflex is solely a consequence of the small pupil physically restricting light-induced constriction $[2,7]$. This hypothesis has been tested by comparing the light reflex in diabetic patients with that in healthy subjects, mostly elderly, who also have small pupils.

\section{Methods}

\section{Subjects}

Seventy-one healthy subjects of both sexes (mean age 45.4 years, range $18-88$ years) and 66 insulin-treated diabetic subjects of both sexes (mean age 39.6 years, range 15-69 years) participated. None of the subjects studied was taking drugs known to interfere with autonomic function. Both groups were selected deliberately to include a large proportion with small resting pupils. The normal group thus in- cluded many elderly subjects since darkness diameter declines with age [1]. The diabetic group included many with autonomic neuropathy with which small pupils are commonly associated $[1,8]$. The patients were graded according to their neuropathic status as follows:

Grade 0: Fourteen had normal peripheral somatic and autonomic nerve function assessed by the tests described below.

Grade 1: Nineteen had peripheral somatic neuropathy, i.e. abnormal vibration sense at toe or ankle on Bio-Thesiometer testing [9] or minimal or absent knee or ankle jerks tested on reinforcement.

Grade 2: Thirty-three had autonomic and peripheral somatic neuropathy. The former was assessed by testing the pupillary and cardiovascular systems by television pupillometry (see below) and measurement of cardiac beat-to-beat variations [10] respectively. Patients were included in this grade if they had a result below the laboratory's normal range in any one of following tests: pupillary dilatation in darkness; standard deviation of 255 successive R-R intervals with the subject resting and supine; mean difference in the shortest and longest $R-R$ interval measured during five successive deep breaths $(5 \mathrm{~s}$ in $; 5 \mathrm{~s}$ out); R-R interval ratio during and following a Valsalva manoeuvre (40 $\mathrm{mmHg}$ pressure for $10 \mathrm{~s}$ ).

\section{Pupillometry}

All pupillary measurements were performed in darkness to which the subjects had adapted by wearing red goggles for a 30-min rest period before the test. Vertical diameters were recorded continuously with an infrared television pupillometer system with the subject focussing on infinity [1]. Light flashes of duration $0.5 \mathrm{~s}$ were directed at the left eye with the light beam focused to a diameter of $1.8 \mathrm{~mm}$ in the plane of the pupil. Light stimulation was thus 'open loop' in that the beam was too small to be diminished in size by a constricting pupil. The intensity of the light was attenuated by insertion of Wratten neutral filters of different densities between the source and the focussing lens system.

In order to control for individual variation in retinal sensitivity, each subject's threshold of visual perception was measured by a forced choice method [11]. At each light intensity three sets of three auditory signals at $3 \mathrm{~s}$ apart were given. One signal in each set was accompanied by a light stimulus. Subjects were told to identify the sig- 


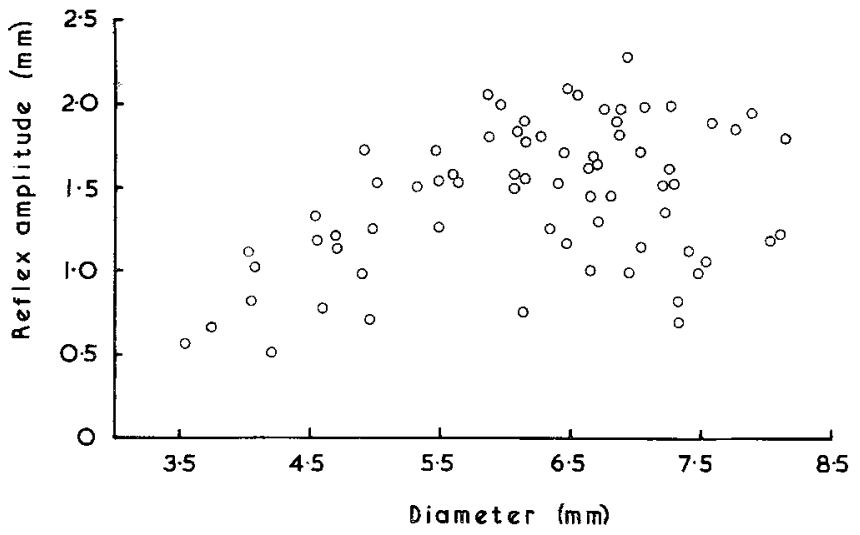

Fig. 1. The relationship between light reflex amplitude and the darkness pupil diameter in 71 healthy subjects. Reflex amplitude was reduced in small pupils (below $6 \mathrm{~mm}$ approximately)

Table 1. Summary of the regression analysis to assess the influence of age $\left(\mathrm{x}_{1}\right)$ and diameter $\left(\mathrm{x}_{2}\right)$ on reflex amplitude $(\mathrm{y})$

\begin{tabular}{lccl}
\hline Source of variation & $\begin{array}{c}\text { Degrees of } \\
\text { freedom }\end{array}$ & $\begin{array}{c}\text { Sum of } \\
\text { squares }\end{array}$ & $p$ \\
\hline Healthy subjects $(n=25)$ & 24 & 4.84 & \\
Total & 1 & 0.29 & $\mathrm{NS}$ \\
$\quad$ Regression on $\mathrm{x}_{1}$ & 1 & 3.13 & $<0.001$ \\
$\quad$ Regression on $\mathrm{x}_{2}$ after $\mathrm{x}_{1}$ & 1 & 3.38 & $<0.001$ \\
$\quad$ Regression on $\mathrm{x}_{2}$ alone & & & \\
Diabetic subjects $(n=43)$ & 42 & 8.18 & \\
Total & 1 & 0.08 & $\mathrm{NS}$ \\
$\quad$ Regression on $\mathrm{x}_{1}$ & 1 & 3.17 & $<0.001$ \\
$\quad$ Regression on $\mathrm{x}_{2}$ after $\mathrm{x}_{1}$ & 1 & 3.11 & $<0.001$ \\
$\quad$ Regression on $\mathrm{x}_{2}$ alone & & & \\
\hline
\end{tabular}

Table 2. Darkness pupil diameters in 66 diabetic subjects graded according to their neuropathic status.

\begin{tabular}{llcc}
\hline & \multicolumn{2}{l}{ Pupil diameter $(\mathrm{mm})$} & \\
\cline { 2 - 4 } & $<3.5$ & $3.5-6.0$ & $>6.0$ \\
\hline Grade 0 & 0 & 5 & 9 \\
Grade 1 & 1 & 13 & 5 \\
Grade 2 & 6 & 25 & 2 \\
Total & 7 & 43 & 16 \\
\hline
\end{tabular}

nals that were accompanied by a flash. Correct identification occurred when the light intensity was above the threshold. Further sets of signals with successively lower intensities of light were then given until the subject made errors. The perception threshold was recorded as the lowest intensity which could be correctly distinguished from no light at all.

The pupillary response to light of an intensity $10^{6}$ times greater than the perception threshold was recorded in each subject. Five $0.5 \mathrm{~s}$ flashes were given at $8 \mathrm{~s}$ intervals and the pupil diameter of the illuminated eye was recorded on a paper trace. The diameter at the foot of the reflex and the response amplitude were obtained by averaging the data from the last four reflexes.

\section{Statistical Analysis}

Sequential multiple linear regression analysis was used to assess the influence of age (first independent variable) and pupil diameter (second independent variable) on the size of the light reflex (dependent variable) [12]. Variation of data about regression lines was described by the $95 \%$ confidence limits. Group means were compared using an unpaired Student's t-test.

\section{Results}

\section{Healthy Subjects}

Light reflex amplitude varied widely from 0.52 to $2.30 \mathrm{~mm}$. The non-linear relationship between the size of the reflex and the resting diameter in darkness is shown in Figure 1. The amplitude appeared to be reduced in small pupils.

This reduction was analysed in the 25 subjects with diameters below $6 \mathrm{~mm}$ to assess the influence of age and resting diameter on reflex amplitude. The age of this group varied from 27 to 88 years (mean 60.5 years). From a simple correlation analysis both age and diameter appear to influence reflex size: correlation coefficients $r=-0.56(p<0.01)$ and $0.84(p<0.001)$ respectively. As diameter decreases with age $(r=-0.58)$, however, it was possible that the decrease in reflex amplitude found with age was due to an interaction with diameter. This possibility was tested by sequential multiple linear regression analysis, a summary of which is shown in Table 1 . This shows that age did not affect reflex amplitude independently from the age-dependent decrease in diameter. Therefore in these healthy subjects the size of the light reflex decreased by $0.55 \mathrm{~mm} / \mathrm{mm}$ decrease in diameter as shown in Figure 2.

\section{Diabetic Subjects}

Forty-three of the diabetic patients tested had darkness diameters in the same range as the normal subjects in whom reflex amplitude was affected by a small pupil size, i.e. between 3.5 and $6 \mathrm{~mm}$. Of the remaining diabetic patients, seven had diameters below and 16 had diameters above this range. The small pupils were found most commonly in the diabetic patients with neuropathy (Table 2).

For the diameters between $3.5-6.0 \mathrm{~mm}$, there was a significant positive correlation between pupil size and reflex amplitude $(r=0.62, p<0.001)$. The slope of the line describing this was not significantly different from that obtained in the healthy subjects. It is clear from Figure 2 that the reflexes were smaller than in normal subjects with similarly reduced darkness pupil diameters. This was confirmed statistically by comparing the deviations of each point (observed - calculated amplitude) from the normal regression line (amplitude $=$ $-1.39+0.55 \mathrm{x}$ where $\mathrm{x}=$ diameter in $\mathrm{mm}$ ). In the normal group $(n=25)$ the mean $( \pm$ SEM) deviation was $0.0 \pm 0.05 \mathrm{~mm}$ as expected; in contrast that in the diabetic group was $-0.34 \pm 0.06 \mathrm{~mm}$. The difference between the two groups was highly significant $(t=4.08$, $p<0.001$ ).

Small pupils in these diabetic patients occurred at a much younger age than in normal subjects: the mean 


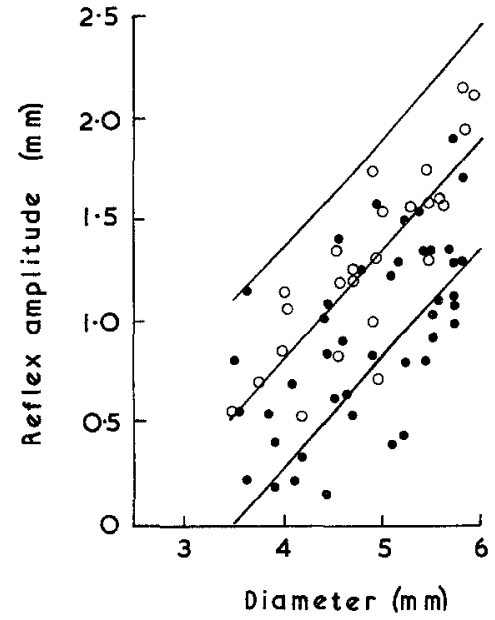

Fig. 2. The reduction of reflex amplitude in 25 healthy [O] and 43 diabetic [ ] subjects with small pupils in the range $3.5-6 \mathrm{~mm}$. The lines drawn show the $95 \%$ confidence limits about the regression line calculated from the 25 healthy subjects

age in these 43 subjects was 39.7 years (range 15-69 years). As in the healthy subjects, age did not affect reflex amplitude independently from its effect on diameter (Table 1).

\section{Discussion}

It has been suggested that the reduced light reflex response in diabetic autonomic neuropathy is solely a consequence of the associated small resting pupil size $[2,7]$. The results of this study do not support this hypothesis. The small pupils of non-diabetic elderly subjects were studied in order to define the degree of restraint on light induced constriction that can be explained by the small pupil. The results in the diabetic subjects show that the reflex reduction exceeds that to be expected from the small pupil alone.

The restriction on reflex amplitude occurred with pupil diameters below $6 \mathrm{~mm}$ in the healthy subjects, in agreement with other reports [13]. An analysis of the anatomical basis for this mechanical limit of constriction has been described [13].

The small pupils of non-diabetic elderly subjects and diabetic neuropaths may have a common aetiology. It is likely that a reduction of sympathetic tone is involved, since in both groups the pupils are supersensitive to phenylephrine $[8,14]$. The marked reflex reduction in the diabetic group may result from a loss of parasympathetic function in addition.

Pathological degeneration can affect the smooth muscles, connective tissue and blood vessels of the iris in diabetic patients with neuropathy [3, 4]. It would not be surprising if these changes restricted its mobility but the findings of normal or enhanced responses to cholinomimetic [5,6] and sympathomimetic [8] drugs do not support this. More work is needed to determine wheth- er the myopathy occurs as a primary process or as a consequence of autonomic neuropathy.

The results presented suggest that diabetic neuropathy affects both branches of the autonomic innervation of the pupil. This contrasts with studies on the autonomic control of heart rate in which parasympathetic dysfunction commonly occurs before any sympathetic dysfunction becomes evident [15]. This discrepancy may be related to the length of the nerve pathways involved: in the pupil the sympathetic nerves follow a longer course than the parasympathetic whereas in the heart the vagal parasympathetic fibres are the longer.

Acknowledgments. This work was supported by the British Diabetic Association and St. Thomas's Hospital Endowments. We are grateful to Professor P.H.Sönksen and Dr. C. Lowy for allowing us to study their patients.

\section{References}

1. Smith SE, Smith SA, Brown PM, Fox C, Sönksen, PH (1978) Pupillary signs in diabetic autonomic neuropathy. $\mathrm{Br}$ Med $\mathrm{J} 2$ : 924-927

2. Hreidarsson AB (1979) Pupil motility in long-term diabetes. Diabetologia 17: 145-150

3. Fujii T, Ishikawa S, Uga S (1977) Ultrastructure of iris muscles in diabetes mellitus. Ophthalmologica 174: 228-239

4. Ohrt V (1968) Diabetic iridopathy. Dan Med Bull 15: 244-248

5. Hayashi M, Ishikawa S (1979) Pharmacology of pupillary responses in diabetics - Correlative study of the responses and grade of retinopathy. Jap J Ophthalmol 23:65-72

6. Sigsbee B, Torkelson R, Kadis G, Wright JW, Reeves AG (1974) Parasympathetic denervation of the iris in diabetes mellitus. $J$ Neurol Neurosurg Psychiatr 37: 1031-1035

7. Gundersen HJG (1976) Nervous and muscular dynamics of the pupil in long-term diabetics. In: Bajaj JS (Ed) Current topics in diabetes research. Excerpta Medica, Amsterdam, pp 131-132

8. Smith SA, Smith SE (1983) Evidence for a neuropathic aetiology in the small pupil of diabetes mellitus. Br J Ophthalmol 67:89-93

9. Smith SA (1982) Reduced sinus arrhythmia in diabetic autonomic neuropathy: the diagnostic value of an age-related normal range. Br med J 285: 1599-1601

10. Smith SE, Smith SA (1981) Heart rate variability in healthy subjects measured with a bedside computer-based technique. Clin Sci 61: 379-383

11. Fison PN, Garlick DJ, Smith SE (1979) Assessment of unilateral afferent pupillary defects by pupillography. Br J Ophthalmol 63: 195-199

12. Snedecor GW, Cochran WG (1967) In: Statistical Methods. Sixth Edition The Iowa State University Press, Ames, Iowa, USA, pp $398-400$

13. Newsome DA, Loewenfeld IE (1971) Iris mechanics II. Influence of pupil size on details of iris structure. Am J Ophthalmol 71: $553-573$

14. Korczyn AD, Laor N, Nemet P (1976) Sympathetic pupillary tone in old age. Arch Ophthalmol 94: 1905-1906

15. Ewing DJ, Campbell IW, Clarke BF (1981) Heart rate changes in diabetes mellitus. Lancet 1:183-185

Received: 9 July 1982

and in revised form: 8 November 1982

Dr. S.A.Smith

Department of Pharmacology

St. Thomas's Hospital Medical School

London SE1 7EH, UK 